\title{
Comparative drug screening in NUT midline carcinoma
}

\author{
A H Beesley ${ }^{\star}, 1$, A Stirnweiss ${ }^{1}$, E Ferrari ${ }^{1}$, R Endersby ${ }^{1}, \mathrm{M} \mathrm{Howlett}{ }^{1}$, T W Failes ${ }^{2}, \mathrm{G} \mathrm{M} \mathrm{Arndt}{ }^{2}, \mathrm{~A} \mathrm{~K}$ Charles $^{3,4}$, \\ $\mathrm{C} \mathrm{H} \mathrm{Cole}{ }^{4}$ and U R Kees ${ }^{1}$ \\ ${ }^{1}$ Division of Children's Leukaemia and Cancer Research, Telethon Institute for Child Health Research, University of Western \\ Australia, Perth, Western Australia; ${ }^{2}$ ACRF Drug Discovery Centre for Childhood Cancer, Children's Cancer Institute Australia for \\ Medical Research, Lowy Cancer Research Centre, UNSW, Sydney, Australia; ${ }^{3}$ Department of Pathology, Princess Margaret \\ Hospital for Children, Perth, Western Australia and ${ }^{4}$ School of Paediatrics and Child Health, University of Western Australia, Perth, \\ Western Australia
}

Background: The NUT midline carcinoma (NMC) is a rare but fatal cancer for which systematic testing of therapy options has never been performed.

Methods: On the basis of disease biology, we compared the efficacy of the CDK9 inhibitor flavopiridol (FP) with a panel of anticancer agents in NMC cell lines and mouse xenografts.

Results: In vitro anthracyclines, topoisomerase inhibitors, and microtubule poisons were among the most cytotoxic drug classes for NMC cells, while efficacy of the bromodomain inhibitor JQ1 varied considerably between lines carrying different BRD4 (bromodomain-containing protein 4)-NUT (nuclear protein in testis) translocations. Efficacy of FP was comparable to vincristine and doxorubicin, drugs that have been previously used in NMC patients. All three compounds showed significantly better activity than etoposide and vorinostat, agents that have also been used in NMC patients. Statins and antimetabolites demonstrated intermediate single-agent efficacy. In vivo, vincristine significantly inhibited tumour growth in two different NMC xenografts. Flavopiridol in vivo was significantly effective in one of the two NMC xenograft lines, demonstrating the biological heterogeneity of this disease.

Conclusions: These results demonstrate that FP may be of benefit to a subset of patients with NMC, and warrant a continued emphasis on microtubule inhibitors, anthracyclines, and topoisomerase inhibitors as effective drug classes in this disease.

The NUT midline carcinomas (NMCs) are rare and extremely aggressive tumours arising in the midline organs and typified by the translocation $\mathrm{t}(15 ; 19)$ (q14;p13.1), which results in a fusion of the BRD4 (bromodomain-containing protein 4) and NUT genes (nuclear protein in testis, otherwise known as C15orf55) (French, 2012; Grayson et al, 2013). Variant NMCs have also been reported whereby NUT is fused to another bromodomain-containing gene, $B R D 3$, or an unknown partner gene (French et al, 2008). First reported in 1991 (Kees et al, 1991; Kubonishi et al, 1991) and originally thought to be a childhood disease, these carcinomas have now been identified in patients ranging from newborn to 78 years of age (French, 2010, 2012; Shehata et al, 2010). NUT midline carcinoma is often misdiagnosed since it is rare, lacks distinct histological features, and is not confined to a particular organ, but increased awareness and the development of an immunohistochemical test to detect aberrant expression of the NUT protein (Haack et al, 2009) has resulted in the number of reported cases steadily rising (Bauer et al, 2012; French, 2012). However both the rarity of the disease and its voracity, with median survival $<7$ months (Bauer et al, 2012), mean that treatment approaches to date have essentially been adapted, without systematic assessment, from those used to treat other types of solid tumour. On the basis

*Correspondence: Dr AH Beesley; E-mail: alex@ichr.uwa.edu.au

Revised 4 December 2013; accepted 9 January 2014; published online 11 February 2014

(c) 2014 Cancer Research UK. All rights reserved 0007-0920/14 
of the involvement of the BRD4 gene in NMC, the newly developed class of bromodomain inhibitors have recently entered clinical trial for this disease (Mirguet et al, 2013) but the results will not be known for some time. Only one survivor of the disease has been reported (Mertens et al, 2007) and a better understanding of alternative treatment options is thus imperative (Bauer et al, 2012).

Flavopiridol (FP, Alvocidib) is a compound originally derived from the bark of an Indian mahogany tree in the 1980s. It has a range of pleiotropic effects that may contribute to its anticancer properties (Newcomb, 2004; Mahoney et al, 2012), but its primary action is thought to be an inhibitor of cyclin-dependent kinases, particularly CDK9 (Blagosklonny, 2004; Parry et al, 2010). Although having had limited success as a single agent in a wide range of early clinical trials (Senderowicz et al, 1998; Thomas et al, 2002; Newcomb, 2004; Whitlock et al, 2005), alternative schedules designed to increase plasma levels have met with much greater success in phase I/II trials of both leukaemias (Lin et al, 2009; Karp et al, 2011; Bose et al, 2012; Karp et al, 2012) and solid tumours (Shah et al, 2005; Rathkopf et al, 2009; Bible et al, 2012; Luke et al, 2012). Notably, BRD4, the gene most commonly translocated to NUT in NMC, is one of several proteins that operate in a complex with CDK9 to regulate transcriptional activation within the cell (Jang et al, 2005; Dow et al, 2010; Schroder et al, 2012), suggesting that targeting this pathway with FP may be an effective therapeutic strategy in NMC. The aim of this study was therefore to compare the efficacy of FP in NMC with that of established and novel antitumour agents.

\section{MATERIALS AND METHODS}

Cell lines and in vitro drug screening. The PER-403 cell line was developed in our laboratory from the first reported case of a patient with a $\mathrm{t}(15 ; 19)(\mathrm{q} 14 ; \mathrm{p} 13.1)$ translocation (Kees et al, 1991), diagnosed at Princess Margaret Hospital, Perth, Western Australia. Following a retrospective review of poorly differentiated paediatric carcinomas of the midline at Princess Margaret Hospital over the last 20 years we have been able to derive two more cell lines (PER624 and PER-704) positively identified as NMC (Table 1). Each of these three lines carries a BRD4-NUT translocation as confirmed by RT-PCR, transcriptome sequencing, and immunoblot, although they vary in regard to exact $B R D 4$ breakpoint position (ThompsonWicking et al, 2013). From a paediatric patient with a high-grade poorly differentiated abdominal carcinoma, we developed the nonNMC cell line PER-535 (Table 1; translocation status confirmed by cytogenetics, immunohistochemistry, and transcriptome sequencing). Cell lines were derived using previously reported methodology (Kees et al, 1991), with approval from the Ethics Committee of the Princess Margaret Hospital for Children, and written informed patient consent. PER-535 and SAOS-2 (a human osteosarcoma cell line from the American Type Culture Collection, ATCC, Manassas, VA, USA) were included in drug screening studies to compare the effect of the tested agents in non-NMC tumour lines. Cell lines were grown in RPMI-1640 medium supplemented with $2 \mathrm{~mm}$ L-glutamine, $10 \mathrm{~nm}$ 2-mercaptoethanol, 10-20\% fetal calf serum, non-essential amino acids, and sodium pyruvate.

Compounds representing either established or emerging anticancer agents $(n=58)$ were identified from the Prestwick Chemical Library (Prestwick Chemical, Illkirch, France). To this list were added vincristine sulphate (Pfizer Australia Pty Ltd, West Ryde, NSW, Australia), the bromodomain inhibitor JQ1 (Dana Faber Cancer Institute, Boston, MA, USA) and flavopiridol (FP; Selleck Chemicals, Houston, TX, USA). Platinum-based drugs (e.g., cisplatin and carboplatin) that are inactivated by DMSO, and the alkylating agents cyclophosphamide and ifosfamide that require activation by liver enzymes, were not included in the screen. Cells in log-phase growth were seeded in 96-well assayready plates using a Multidrop 384 (Thermo Scientific, Waltham, MA, USA) and incubated for 4 days at $37^{\circ} \mathrm{C}$ in the presence of the indicated drug or vehicle (DMSO). Library screening to identify lead compounds was performed at a fixed dose of $10 \mu \mathrm{M}$, with IC50 values subsequently determined in independent experiments. Response to drug treatment was determined using the Alamar Blue assay according to standard protocols. Briefly, Alamar Blue reagent $(10 \% \mathrm{v} / \mathrm{v})$ was dispensed to assay plates using a Multidrop Combi (Thermo Scientific) and following a 6-h incubation at $37^{\circ} \mathrm{C}$ metabolic activity was determined by measurement of fluorescence intensity (ex $555 \mathrm{~nm}$, em $585 \mathrm{~nm}$ ) using a SpectraMax M5 plate reader (Molecular Devices, Sunnyvale, CA, USA). Percentage cell viability was calculated relative to positive and negative (vehicle only) controls.

NMC xenografts and treatment. Subcutaneous flank engraftments in immunocompromised mice were performed as previously described (White et al, 2001). Briefly, cells $\left(1 \times 10^{6}\right)$ in log-phase growth were resuspended in a $1: 1$ mixture of culture medium and Matrigel (BD Biosciences, San Jose, CA, USA) and subcutaneously injected into the flanks of 8 - to 10 -week-old female nude mice (Balb/c nu/nu) in a final volume of $100 \mu \mathrm{l}$ (6-10 mice per treatment group). Tumour growth was measured daily using calipers, and volume calculated using the formula ((length $x$ width $\left.^{2}\right) / 2$ ). Drug treatments began 1 week after engraftment (day 7 ), and mice were euthanised when tumours reached $1500 \mathrm{~mm}^{3}$ or upon observation of adverse health. Treatment with FP (stock solution $1 \mathrm{mg} \mathrm{ml}^{-1}$, flavopiridol hydrochloride; Selleck Chemicals) or vehicle (5\% dextrose solution) was by daily intraperitoneal (i.p.) injection $\left(5 \mathrm{mg} \mathrm{kg}^{-1}\right.$ per day FP or vehicle) for five consecutive days (Mon-Fri), repeated over 4 weeks. Vincristine sulphate (Pfizer Australia Pty Ltd) or vehicle (PBS) was administered at

Table 1. Cell line panel used for drug screening

\begin{tabular}{|c|c|c|}
\hline Cell line & Patient diagnosis & NMC translocation \\
\hline PER-403 & $\begin{array}{l}\text { 11-year female; poorly differentiated intrathoracic squamous carcinoma, } \\
\text { possible thymic origin }\end{array}$ & $\mathrm{t}(15 ; 19)(q 14 ; p 13.1)$ : BRD4-NUT (Exon 11: Exon 2) (Kees et al, 1991) \\
\hline PER-624 & $\begin{array}{l}\text { 16-year female; poorly differentiated aggressive lung carcinoma, complex } \\
\text { karyotype }\end{array}$ & $\begin{array}{l}\mathrm{t}(6 ; 19)(q 13 ; p 13.1): \text { Cryptic BRD4-NUT (Exon 15: Exon 2) } \\
\text { (Thompson-Wicking et al, 2013) }\end{array}$ \\
\hline PER-704 & 8-year male; poorly differentiated laryngeal carcinoma & $\mathrm{t}(15 ; 19)(q 14 ; p 13.1):$ BRD4-NUT (Exon 15: Exon 2) \\
\hline PER-535 & $\begin{array}{l}\text { 13-year female; high-grade poorly differentiated abdominal tumour with } \\
\text { neuroectodermal features }\end{array}$ & Non-NMC \\
\hline SAOS-2 & 11-year female; osteogenic sarcoma & Non-NMC \\
\hline
\end{tabular}


$0.5 \mathrm{mg} \mathrm{kg}^{-1}$ per week over a 6-week period (i.p. delivery once per week). For in vivo imaging of PER-624, cells were infected with retrovirus driving expression of a fusion protein consisting of puromycin acetyl transferase and the luciferase-reporting gene Luc2. Luciferase expression was confirmed in vitro by luciferase assay (Promega, Auburn, VIC, Australia). In vivo engraftment of luciferase-expressing PER-624 cells (denoted as PER-624luc) was monitored weekly using a Xenogen IVIS Spectrum (Caliper Life Sciences, Hopkinton, MA, USA). Mice were injected i.p. with $200 \mu \mathrm{l}$ of a $15 \mathrm{mg} \mathrm{ml}^{-1}$ luciferin solution (XenoLight D-Luciferin $\mathrm{K}^{+}$Salt Firefly; Caliper Life Sciences) in PBS, 5 min before imaging to allow uptake of the substrate and all data were collected as photons/second. Ethical approval for all in vivo experiments was obtained from the Animal Ethics Committee of the Telethon Institute for Child Health Research.

Tumour analyses. For immunohistochemistry, harvested tumour tissue was fixed in $10 \%$ neutral-buffered formalin. Following rehydration, heat-mediated antigen retrieval, peroxidase quenching and blocking, $4 \mu \mathrm{m}$ paraffin sections were stained for NUT (C52B1 antibody; Cell Signaling Technology, Boston, MA, USA) or cytokeratin (AE1/3 antibody; Dako, Carpinteria, CA, USA), and counterstained with Carazzi's Haematoxylin. For detection of the expression of the BRD4-NUT fusion by RT-PCR, primers were targeted to exon 7 of NUT, a gene that is not normally expressed outside the testis. RNA was extracted from snap-frozen tumour tissue (TRIzol; Invitrogen, Mulgrave, VIC, Australia), purified (Rneasy Mini RNA extraction Kit; Qiagen, Valencia, CA, USA), reverse transcribed (SuperScript VILO cDNA Synthesis Kit; Qiagen), and amplified using Q5 High-Fidelity DNA Polymerase (New England BioLabs Inc., Ipswich, MA, USA). Primer sequences were $3^{\prime}$-GGGAACCAGGAATGCCATA-5' and $3^{\prime}$-GCTCTCTGG CTGCCCTGA- $5^{\prime}$.

\section{RESULTS}

Drug class comparison in NMC cell lines. Using three NMC cell lines established in our laboratory, we assessed the relative cytotoxicity of 61 anticancer compounds representing 17 distinct drug classes, at a fixed dose of $10 \mu \mathrm{M}$ (Figure 1A). We performed unsupervised hierarchical clustering on viability to identify patterns of response among the drug classes. From this, we identified a distinct group of drug classes associated with strong cytotoxicity in at least two of the three cell lines (in particular, the anthracyclines, microtubule inhibitors, topoisomerase inhibitors, several of the antimetabolites, and the CDK9 inhibitor FP), as well as a group of drugs with intermediate cytotoxicity or variable responses between the lines (e.g., the statins, the other antimetabolites, and the bromodomain inhibitor JQ1). The EGFR inhibitors yielded significant cytotoxic responses in only PER-624, suggesting that there may be alterations to this signalling pathway in this particular cell line. Approximately half of the tested compounds had little to no cytotoxicity at this $10 \mu \mathrm{M}$ dose (including the steroids, steroid-receptor antagonists, aromatase inhibitors, AMPK agonists, inhibitors of fatty acid metabolism, and VEGF inhibitors).

We averaged the effect of drugs within their classes to derive a ranking of the relative efficacy of each drug class against NMC cell lines (Figure 1B). Flavopiridol was one of the most effective drugs at this $10 \mu \mathrm{m}$ dose, along with the anthracyclines, topoisomerase inhibitors, and microtubule inhibitors. The statins and antimetabolites demonstrated intermediate responses, along with the histone deacetylase inhibitor vorinostat and the bromodomain inhibitor JQ1. Given its targeted mechanism of action it was initially surprising that JQ1 did not rank higher, however, subsequent dose-response testing revealed that its efficacy was dramatically different between the three NMC cell lines (Figure 1C; IC50 values 3.6 nм PER-403, 266 nм PER-704, and $11 \mu \mathrm{M}$ PER-624). PER-403 carries a different BRD4-NUT breakpoint (involving exon 11 of BRD4) to PER-624 and PER-704 (both involving exon 15 of BRD4; Thompson-Wicking et al, 2013) and it is possible that this difference affects drug efficacy. However, there are likely to be additional biological or genomic differences between these lines that contribute to their pattern of drug sensitivity and the exact reason for the differential in their responses remains to be determined.

From each of the top drug classes in Figure 1B, we selected compounds for further dose-response testing in NMC cell lines (Figure 1D). These were FP (a CDK9 inhibitor), daunorubicin (an anthracycline), vincristine (a microtubule inhibitor), simvastatin (a statin), vorinostat (a histone deacetylase inhibitor), and etoposide (a topoisomerase inhibitor). The mean IC50 of FP in NMC cell lines was $18.4 \pm 1.8 \mathrm{~nm}$, two orders of magnitude lower than either etoposide $(2.4 \pm 2 \mu \mathrm{M})$ or vorinostat $(1.6 \pm 0.5 \mu \mathrm{M})$, agents that have both been previously used to treat NMC patients. Simvastatin, a drug that is not traditionally thought of as an anticancer agent, demonstrated similar efficacy to etoposide and vorinostat (IC50 $2.7 \pm 0.8 \mu \mathrm{M})$. Overall, the FP IC50 in NMC lines was most comparable to vincristine $(3.5 \pm 0.7 \mathrm{nM})$ and daunorubicin $(32 \pm 23 \mathrm{~nm})$, conventional chemotherapeutic agents that, like etoposide and vorinostat, have previously been used in the treatment of NMC. The averaged JQ1 response across the three cell lines (mean IC50 $3.8 \pm 3.6 \mu \mathrm{M}$ ) is indicated on this graph for reference, noting that the IC50 for JQ1 in PER-403 (3.6 nM) was comparable to that of vincristine.

We then compared these responses with those of two nonNMC cell lines, PER-535 and SAOS-2 (Figure 2A). The IC50 for FP was consistently lower in NMC $v s$ non-NMC lines $(P<0.001$, multiple testing corrected unpaired $t$-test). Although this panel is too small to draw definitive conclusions, the differential in response suggests there could be a selective benefit of the drug in NMC. Responses to FP were very reproducible (Figure 2B) with cytotoxicity occurring within a remarkably tight dose range, an observation we have also made when using this drug in other cancers (Beesley et al, 2007). The IC50 profiles of the drugs across the five cell lines are provided as a heatmap in Figure 2C, and dose-response curves for simvastatin, vincristine, etoposide, vorinostat, and JQ1 are provided in Figure 2D and Supplementary Figure S1A-D, respectively. Finally, we also tested the relative sensitivity of the five lines to $\gamma$-irradiation, since wildtype BRD4 is known to functionally partner with p53 (Wu et al, 2013) and have a role in insulating chromatin from the effects of DNA damage (Floyd et al, 2013), and NMC patients respond reasonably well to radiotherapy (Bauer et al, 2012). Each cell line in log-phase growth was exposed to graded doses from 1 to 20 Gys and viability measured after 4 days. There was no consistent difference in response between NMC and non-NMC lines (Figure 2E). PER-403 was the most sensitive of the NMC lines to $\gamma$-irradiation, with mean survival at the maximal dose ranging from 25\% (PER-403) to 56\% (PER-704). PER-403 therefore appears to have the greatest sensitivity of the three NMC lines to DNA damage induced by $\gamma$-irradiation.

Establishment and treatment of NMC xenografts. To evaluate the most promising compounds in vivo, we established NMC xenografts. Engraftment of NMC cell lines into the flanks of nude mice generated tumours with different growth kinetics, with PER624 and PER-403 xenografts reaching end point $\sim 20$ days and 40 days, respectively, but with PER-704 showing significantly slower engraftment (Figure 3A). Histological analysis of PER-624 tumours revealed sheet-like tumour growth with interstitial hyaline and extensive necrosis. Tumours from PER-403 xenografts demonstrated broad, rather nodular growth with fibrous stoma and less 


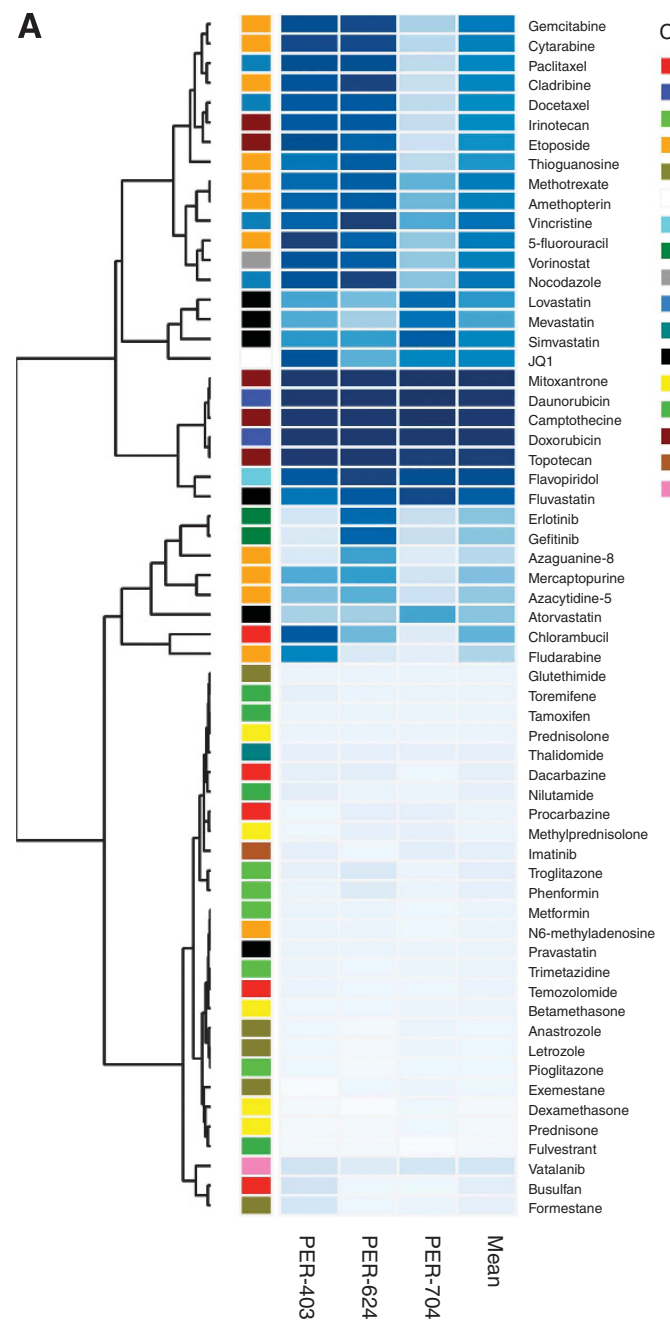

Class

- Alkylating agent

- Anthracycline

- Anti-diabetic

Anti-metabolite

Aromatase inhibitor

Bromodomain inhibitor (JQ1)

CDK9 inhibitor (FP)

EGFR inhibitor

Histone deacetylase inhibitor

- Microtubule poison

- Nuclear redox modulator

Statin

Steroid

Steroid receptor antagonist

Topoisomerase inhibitor

Tyrosine kinase inhibitor

VEGF inhibitor

$$
\frac{\text { 웅 웅 이 }(10 \mu \mathrm{M})}{\% \text { Cell }}
$$

B

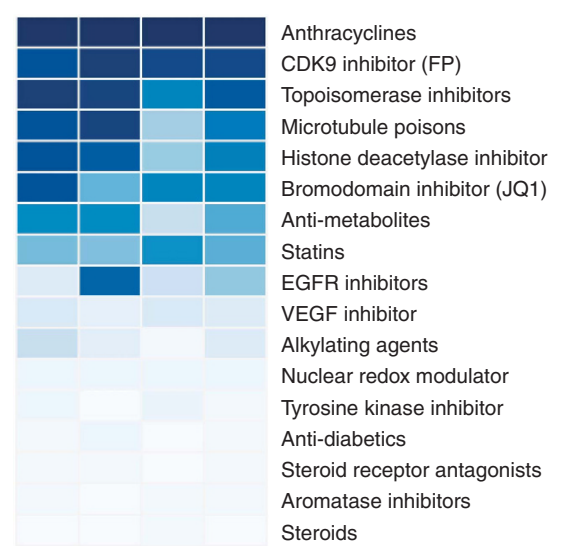

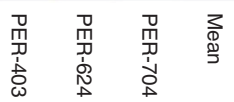

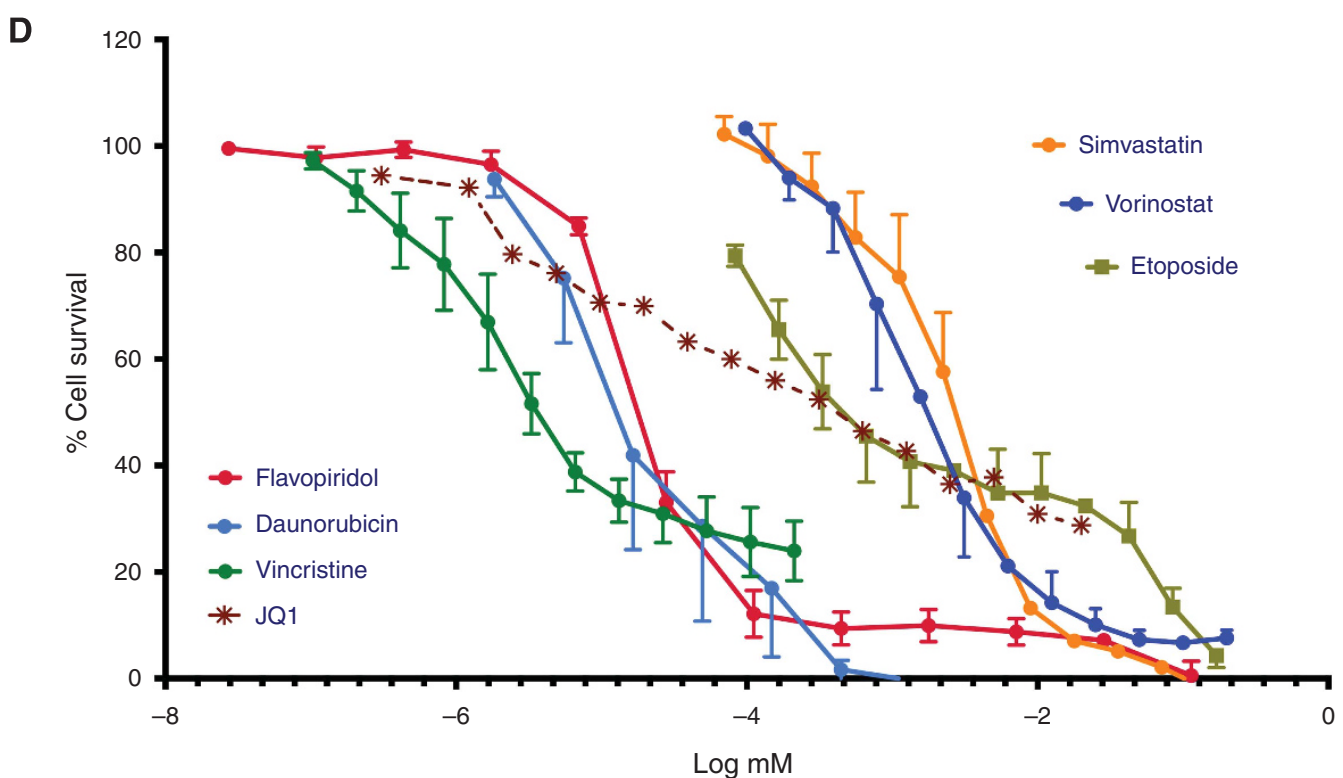

Figure 1. Comparative efficacy of anticancer agents in NMC cell lines. (A) Unsupervised hierarchical clustering of anticancer agents from the Prestwick Chemical Library (plus vincristine, FP, and JQ1) based on cytotoxicity (\% cell kill) in NMC lines at $10 \mu \mathrm{m}$. Multiple drug classes are represented, as indicated by the coloured key; (B) The most effective drug classes were identified by averaging the $10 \mu \mathrm{m}$ cytotoxic effect of agents within each class across all three NMC cell lines (heatmap ranked by mean \% cell kill); (C) In vitro cytotoxicity of the bromodomain inhibitor JQ1 in NMC cell lines (mean \pm s.e.m.), with five independent experiments per cell line; (D) Relative efficacy of the indicated drugs in NMC cell lines, with data representing the averaged values ( \pm s.e.m.) for the three NMC cell lines (PER-403, PER-624, and PER-704) with the exception of JQ1 which is shown without error bars for clarity (refer to $\mathbf{C}$ for individual cell line response to this agent). 

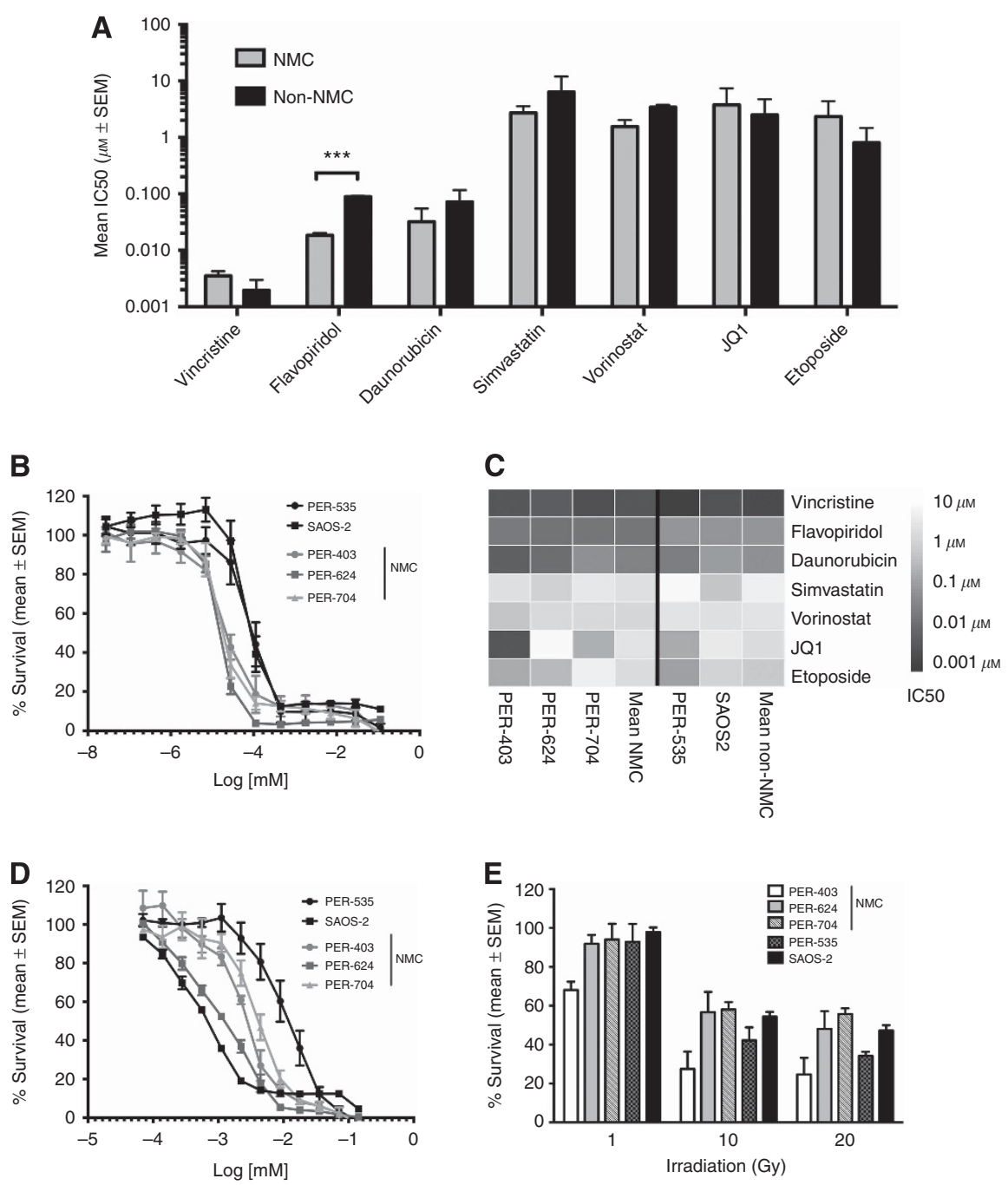

Figure 2. Comparative efficacy of anticancer therapies in NMC vs non-NMC cell lines. (A) Mean IC50 ( \pm s.e.m.) of the indicated agents in three

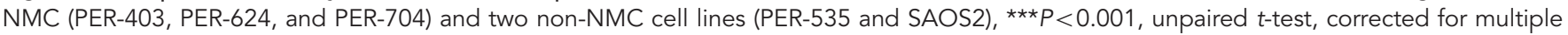
testing; (B) In vitro cytotoxicity of FP in NMC (grey symbols) and non-NMC cell lines (black symbols), with 3-4 independent experiments per cell line; (C) Heatmap of averaged IC50 values across the five cell lines for the indicated drugs $(n=3-5$ independent experiments per drug and per cell line); (D) In vitro cytotoxicity of NMC (grey symbols) and non-NMC cell lines (black symbols) to simvastatin ( $n=4-5$ independent experiments per cell line); (E) Survival of NMC (light bars) and non-NMC cell lines (dark bars) $96 \mathrm{~h}$ after $\gamma$-irradiation at the indicated doses ( $n=5$ independent experiments per cell line).

necrosis (possibly linked to slower growth rate) resulting in firmer tumours than for PER-624. There was no evidence in either xenograft of spread to other organs. Tumour histology from both xenografts was poorly differentiated, with immunohistochemistry demonstrating the extensive speckled nuclear staining for NUT and the absence of cytokeratin (a marker for epithelial differentiation) that is the hallmark of NMC (Figure 4, control tissues). In both cases tumour morphology and the pattern of NUT staining in xenograft-derived tumours were comparable to that of the primary patient tumours from which each of the NMC cell lines was derived (Figure 5). To test the efficacy of FP against NMC in vivo, tumour growth and survival were assessed in mice xenografted with PER-624 and administered $5 \mathrm{mg} \mathrm{kg}^{-1}$ per day FP in 20 injections over 4 weeks. This regimen significantly slowed in vivo tumour growth compared with vehicle-treated animals (Figure 3B), and prolonged survival (median 16 days vs 28 days respectively, $P<0.005$ log-rank test, Figure 3C) without adverse toxicity. Immunohistochemistry revealed no discernable difference in either NUT or cytokeratin expression between tumours from treated or untreated animals (Figure 4A), indicating that the effect of FP was cytotoxic rather than via an effect on tumour differentiation.
This study was repeated using PER-624 luciferase-labelled cells, designated as PER-624luc, to enable in vivo imaging of tumour growth. Supplementary Figure S2A shows the typical growth of PER-624luc tumours in vehicle and FP-treated animals, with no evidence of dissemination from the site of engraftment. As in the parental cell line, PER-624luc xenografts also demonstrated delayed tumour growth and prolonged survival in response to $5 \mathrm{mg} \mathrm{kg}^{-1}$ per day FP (median survival 21 days $v s 43.5$ days in vehicle-treated controls, $P<0.001$ log-rank test; Supplementary Figure S2B). These findings contrast with the PER-403 xenografts where we did not record a significant effect of FP treatment on tumour growth (Figure 3D), despite the fact that the drug was equally cytotoxic against these two lines in vitro (Figure $2 \mathrm{~B}$ ). RT-PCR for NUT, indicative of expression of the BRD4-NUT fusion, was positive in tumours from both PER-403 and PER-624 xenografts at experiment end point (Supplementary Figure S3). The reason for the dramatic differences in response to this drug between the two lines in vivo may be related to their different engraftment kinetics (Figure 3A), and thus a relationship between FP and tumour metabolism or rate of cell division. Since these two lines carry different BRD4-NUT translocations, there may be 

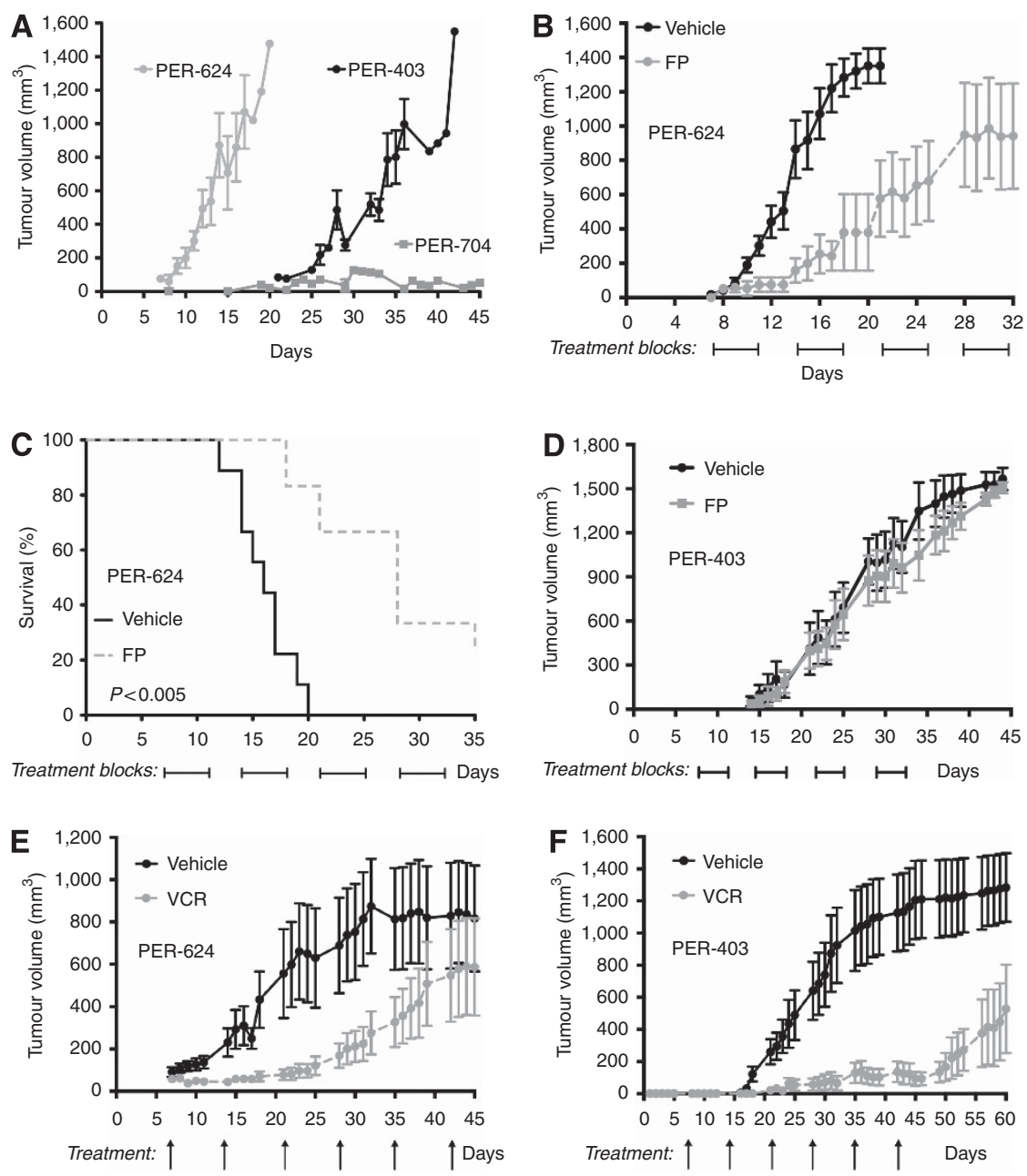

Figure 3. In vivo drug treatment of NMC xenografts. (A) Comparison of engraftment kinetics for PER-403, PER-624, and PER-704 (mean \pm s.e.m.); (B) Effect of FP ( $5 \mathrm{mg} \mathrm{kg}^{-1}$ per day $\times 4$ weeks) on PER-624 in vivo tumour growth (difference to day 21, $P<0.001$, two-way ANOVA); (C) Effect of FP $\left(5 \mathrm{mg} \mathrm{kg}^{-1}\right.$ per day $\times 4$ weeks) on overall survival in PER- 624 xenografted mice $\left(P<0.005\right.$, log-rank test); (D) Effect of FP $\left(5 \mathrm{mg} \mathrm{kg}{ }^{-1}\right.$ per day $\times 4$ weeks) on PER-403 in vivo tumour growth (mean \pm s.e.m.); (E) Effect of vincristine (VCR, $0.5 \mathrm{mg} \mathrm{kg}^{-1}$ per week) on tumour growth in PER-624 xenografts $\left(P<0.001\right.$, two-way ANOVA); $(F)$ Effect of vincristine $\left(V C R, 0.5 \mathrm{mg} \mathrm{kg}^{-1}\right.$ per week) on tumour growth in $P E R-403$ xenografts $(P<0.001$, two-way ANOVA).

important differences in BRD4 and/or CDK9 signalling that relate to both growth pattern and FP sensitivity in an in vivo context. Alternatively, given the tight threshold for in vitro cytotoxicity of this drug (Figure 2B), it is conceivable that higher doses or a longer treatment schedule (beyond 4 weeks) is required to observe an effect of FP in the PER-403 xenograft.

To benchmark this result, we compared the in vivo efficacy of FP with vincristine, a drug that has often been used to treat NMC patients, and which was one of the most effective agents in our in vitro screen. Treatment with vincristine significantly slowed tumour growth in both PER-624 and PER-403 xenografts (Figure 4E and $\mathrm{F}$, respectively), but with the response being much more striking in the latter, with almost complete suppression of growth during the treatment phase. These tumours quickly expanded however once vincristine treatment ceased (Figure 4F), analogous to the clinic where NMC patients typically respond to initial therapy but quickly relapse. This is the first time that vincristine has been demonstrated to be effective in an in vivo model of the disease and our findings support its continued use in NMC patients. The contrasting pattern of sensitivity of these NMC lines to FP and vincristine in vivo reinforces the biological heterogeneity of this disease and the need for empirical testing of both novel and conventional agents.

\section{DISCUSSION}

Therapies that have historically been used to treat NMC patients include $\gamma$-irradiation and varying combinations of vincristine, etoposide, daunorubicin, doxorubicin, cisplatin, docetaxel, dexamethasone, prednisolone, ifosfamide, and cyclophosphamide (Kees et al, 1991; Kubonishi et al, 1991; Engleson et al, 2006; Mertens et al, 2007; Fujioka et al, 2010; Bauer et al, 2012). However, due to the rarity of NMC there has been no systematic preclinical or clinical assessment of these agents, and in contrast to the demonstrated benefit of surgical resection and radiotherapy, no chemotherapeutic regimen has as yet been associated with improved outcome in this disease (Bauer et al, 2012). With this in mind it is imperative to establish the baseline efficacy of such compounds to interpret the potential benefit of alternative approaches. Using a high-throughput screening approach, we found that the microtubule inhibitors, anthracyclines, and certain topoisomerase inhibitors were particularly potent in NMC and such drug classes may therefore represent the best starting point for the future development of combination chemotherapy approaches. Such regimens are likely to include recently identified bromodomain and extra-terminal domain (BET) inhibitors, 

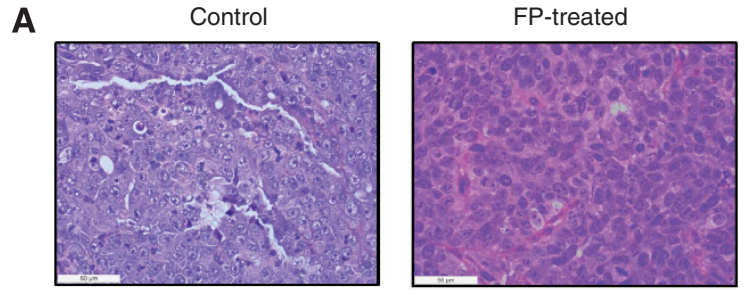

$\mathrm{H} \& \mathrm{E}$
$(\mathrm{x} 40)$
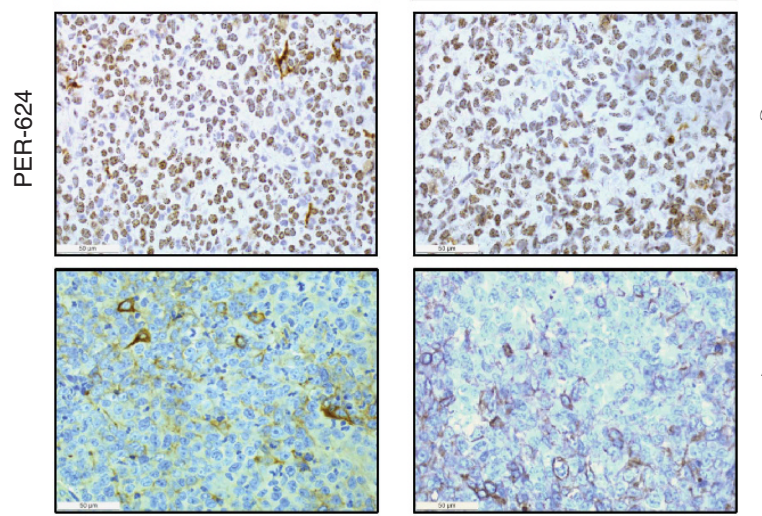

B
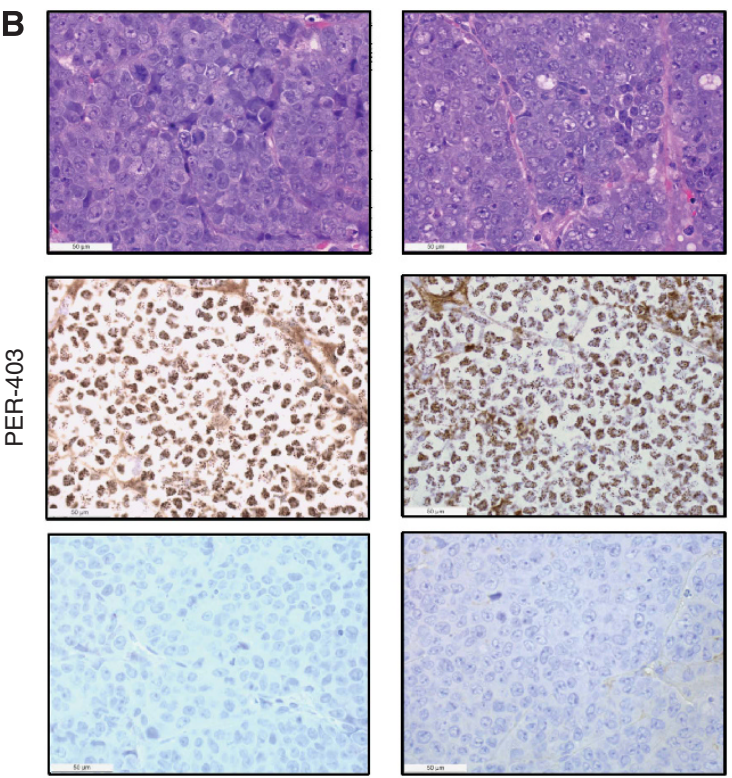

$H \& E$

$(\mathrm{x} 40)$

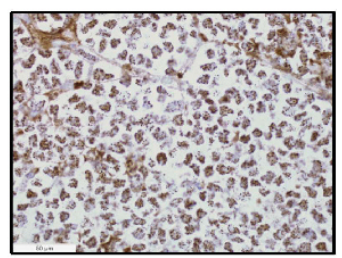

$\mathrm{AE} 1 / 3$

$(\mathrm{x} 40)$

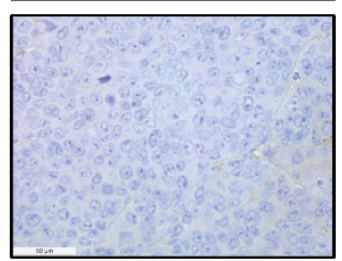

Figure 4. Comparison of control and FP-treated tumours from (A) PER-624 or (B) PER-403 xenografts. Images show haematoxylin \& eosin (H\&E) staining, IHC for NUT ( $\alpha$-NUT), and cytokeratin (AE1/3), with brown immunopositive stain and blue haemotoxylin nuclear counterstain. In each case, tumours were poorly differentiated, with cells demonstrating large nuclei and prominent nucleoli, scant cytoplasm with little cytokeratin and extensive speckled nuclear staining for NUT. There was no discernable difference between tumours from control and FP-treated xenografts in either line.

which directly bind BRD4 and other BET family members (Belkina and Denis, 2012; Prinjha et al, 2012), and have been shown to have promising efficacy both in NMC (Filippakopoulos et al, 2010) and in a variety of other cancers (Dawson et al, 2011; Delmore et al, 2011; Zuber et al, 2011; Lockwood et al, 2012; Ott et al, 2012). The first phase I clinical trial for use of the BET inhibitor GSK525762 (I-BET762) in NMC is currently open in the United States (Mirguet et al, 2013) and an international registry for NMC has recently been established to facilitate the recruitment of patients (www.nmcregistry.org). However, the results from the present study using the BET inhibitor JQ1 suggest that there may be a
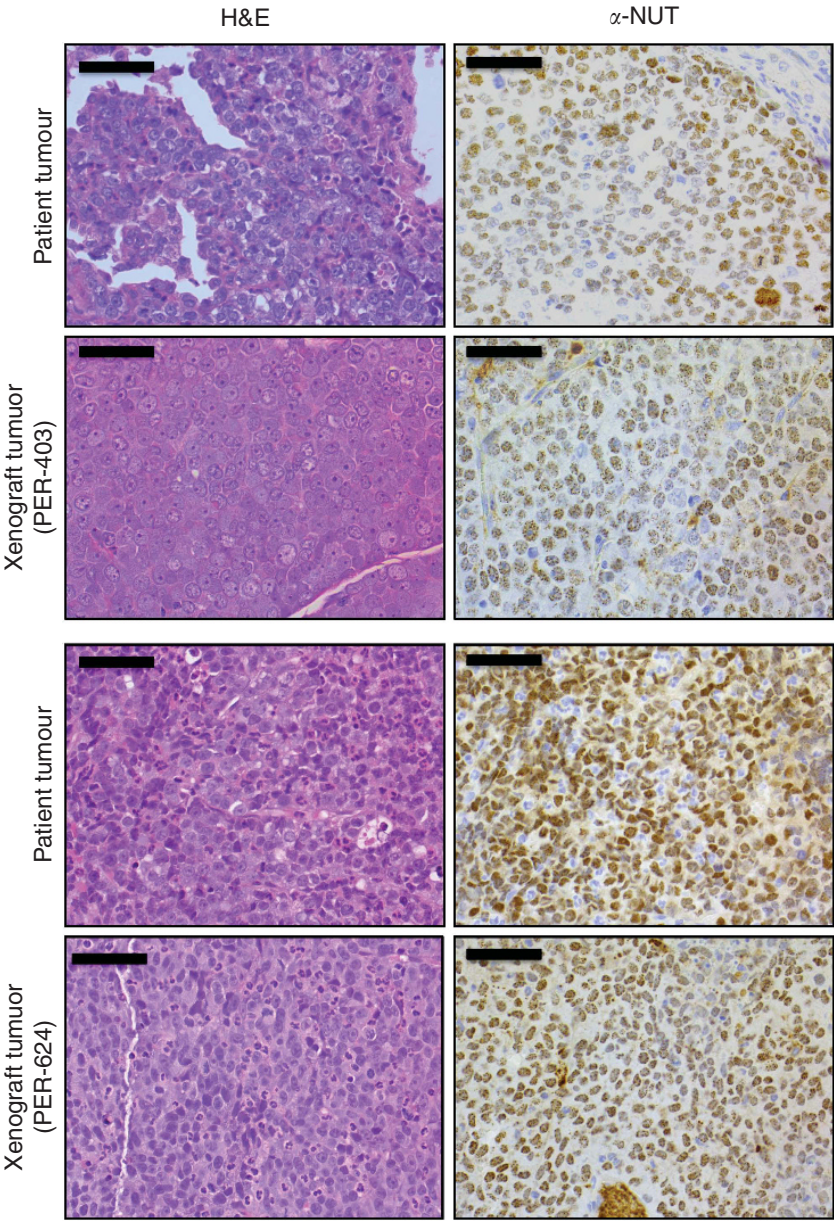

Figure 5. Histological comparison of NMC xenograft tumours (PER403 and PER-624) with the primary patient tumours from which each cell line was derived; left panel, haematoxylin \& eosin (H\&E); right panel, anti-NUT IHC ( $\alpha$-NUT, brown; haematoxylin counterstain, blue), magnification $\times 40$, bars $50 \mu \mathrm{m}$. All tumours were poorly differentiated, with cells demonstrating large nuclei with prominent nucleoli, scant cytoplasm and extensive speckled nuclear staining for NUT. A small but similar proportion ( $\sim 10 \%)$ of cells in each tissue was negative for NUT. Alveolar structures are visible in the primary tumour (top panel) used to derive PER-403.

significant variability in the response to this drug class. Whether this is related to particular BRD4-NUT translocations remains to be determined, but if so, patients may ultimately need to be stratified for the most appropriate treatment.

Interest in the histone deacetylase inhibitor vorinostat as a potential therapy for NMC has arisen through studies linking expression of the BRD4-NUT fusion protein with global changes in chromatin acetylation in NMC cells (Reynoird et al, 2010; Schwartz et al, 2011). Early indications in mouse xenografts demonstrated promising efficacy of this compound in NMC, and in a single patient, vorinostat treatment resulted in dramatic disease regression before adverse toxicity limited its use (Schwartz et al, 2011). Despite the biological rationale for vorinostat use in NMC, however, the IC50 of this compound in the present study was in the micromolar range, significantly higher than that of vincristine or daunorubicin. The efficacy of vorinostat was comparable to that observed with the HMGCoA-reductase inhibitor simvastatin, a drug that has gained attention in recent years for its potential anticancer properties along with other members of the statin family (Hindler et al, 2006; Han et al, 2011). In large part, this is due to an increased awareness of the 
importance of altered sugar and lipid metabolism for tumour growth, the so-called Warburg phenotype (Beesley et al, 2009; Tennant et al, 2010). Statins are FDA-approved agents associated with minimal toxicity and have been tested in a number of solid tumours and leukaemias (Hindler et al, 2006; Han et al, 2011). While also less potent than vincristine and daunorubicin, simvastatin was at least comparable in efficacy to the topoisomerase inhibitor etoposide, which has a history of use in NMC therapy. Given its excellent safety profile and distinct mechanism of action from most other chemotherapeutics, it may be a candidate for inclusion in future combination approaches.

In our drug screen, we found that the CDK9 inhibitor FP was one of the most cytotoxic drugs against NMC cell lines in vitro, and were able to demonstrate significant in vivo responses in PER-624 xenografts, the first time to our knowledge that this agent has been evaluated in NMC. We observed no adverse toxicity from the use of this drug in vivo. Although both CDK9 and wild-type BRD4 are part of the positive transcription elongation factor complex P-TEFb (Jang et al, 2005; Dow et al, 2010; Schroder et al, 2012), it is not currently known whether the oncogenic BRD4-NUT fusion protein expressed in NMC also interacts with the CDK9 complex (one of the primary targets of FP). Deregulation of this signalling pathway in NMC may potentially account for the efficacy of FP in NMC but the drug has a number of other biological effects that could contribute to its cytotoxicity (Newcomb, 2004; Mahoney et al, 2012). There may be additional effects of FP (via CDK9) on wild-type BRD4 signalling from the non-translocated allele present in these cells. Failure to observe an effect of FP in PER-403 xenografts suggests that differences in $B R D 4-N U T$ translocation and growth in vivo are important determinants of response to this drug in NMC.

It should be noted that, in other cancers, problems in the use of FP has been related to dosing achievable in vivo. The most successful trials involving this drug as a single agent have been reported in patients with chronic lymphocytic leukaemia where bolus dosing schedules were developed to maximise free plasma concentrations of the drug, which has been shown to be highly protein bound (Byrd et al, 2007; Lin et al, 2009). Pharmacokinetic data from phase I leukaemia trials using such schedules indicate that unbound FP plasma concentrations are approximately one tenth of total FP plasma levels and reach 141-168 nM (infusion/ bolus) at maximally tolerated doses, with side effects mainly related to tumour lysis syndrome (Karp et al, 2011). In some studies, direct bolus administration of FP has achieved even higher plasma levels (Karp et al, 2012; Luke et al, 2012). On the basis of the IC50 for FP in the present study, the achievable plasma concentrations of unbound FP reported from these clinical trials would be expected to be effective against NMC tumours in vivo, as indeed was the case for PER-624. In other solid tumours encouraging responses have been reported from the use of FP in combination with irinotecan (Shah et al, 2005), doxorubicin (Luke et al, 2012), cisplatin (Bible et al, 2012), and other agents (Rathkopf et al, 2009), although it is clear that the order in which these drugs are delivered in combination may be a critical factor for success (Shah et al, 2005; Karp et al, 2012; Luke et al, 2012). Given that there is currently no effective treatment for NMC and the survival time is measured only in months (Bauer et al, 2012), the favourable comparison of FP with several agents so far used in NMC patients, along with its demonstrated clinical tolerability, suggests that its use in this disease should be considered. Finally, our results support the continued use of vincristine, which significantly reduced tumour burden in both NMC xenografts, as an effective agent in the treatment of this disease. Wild-type BRD4 expression has been shown to be required for recovery from drug-induced mitotic stress (Nishiyama et al, 2006, 2012), providing a biological rationale for the sensitivity of NMC cells to antimicrotubule agents since they are typically haploinsufficient for wild-type BRD4.
It is clear however that while vincristine significantly slowed tumour growth in these models, it was not sufficient to prevent tumour re-emergence, which is the ultimate clinical challenge for such patients. With the establishment of this model we now have the opportunity to formally assess drugs and novel combinations in vivo for their effectiveness in NMC and their potential to prevent disease recurrence.

\section{ACKNOWLEDGEMENTS}

We would like to thank the patients and the parents with whom this study is connected, Ms Maxine Crook, PathWest Laboratory Medicine Perth, for tumour processing and immunohistochemistry, and Ms Denise Anderson, Bioinformatics and Data Services, Telethon Institute for Child Health Research, for clustering and statistical analyses. The MSCV-pacLuc2 and pCAG-VSVG plasmids used to generate luciferase-expressing retrovirus were generous gifts from Dr Richard Williams and Dr Arthur Nienhuis, St Jude Children's Research Hospital, Memphis, USA. The bromodomain inhibitor JQ1 was provided by Dr J Bradner, Dana Faber Cancer Institute (DFCI). This research was funded by the Children's Leukaemia and Cancer Research Foundation, and the Telethon Adventurers, Perth, Western Australia.

\section{CONFLICT OF INTEREST}

The authors declare no conflict of interest.

\section{REFERENCES}

Bauer D, Mitchell C, Strait K, Lathan C, Stelow E, Lueer S, Muhammed S, Evans A, Sholl L, Rosai J, Giraldi E, Oakley R, Rodriguez-Galindo C, London W, Sallan SE, Bradner J, French CA (2012) Clinicopathologic features and long-term outcomes of NUT midline carcinoma. Clin Cancer Res 18: 5773-5779.

Beesley AH, Firth MJ, Ford J, Weller RE, Freitas JR, Perera KU, Kees UR (2009) Glucocorticoid resistance in T-lineage acute lymphoblastic leukaemia is associated with a proliferative metabolism. $\mathrm{Br}$ J Cancer 100: 1926-1936.

Beesley AH, Palmer ML, Ford J, Weller RE, Cummings AJ, Freitas JR, Firth MJ, Perera KU, De Klerk NH, Kees UR (2007) In vitro cytotoxicity of nelarabine, clofarabine and flavopiridol in paediatric acute lymphoblastic leukaemia. Br J Haematol 137: 109-116.

Belkina AC, Denis GV (2012) BET domain co-regulators in obesity, inflammation and cancer. Nat Rev Cancer 12: 465-477.

Bible KC, Peethambaram PP, Oberg AL, Maples W, Groteluschen DL, Boente M, Burton JK, Gomez Dahl LC, Tibodeau JD, Isham CR, Maguire JL, Shridhar V, Kukla AK, Voll KJ, Mauer MJ, Colevas AD, Wright J, Doyle LA, Erlichman C (2012) A phase 2 trial of flavopiridol (Alvocidib) and cisplatin in platinresistant ovarian and primary peritoneal carcinoma: MC0261. Gynecol Oncol 127: 55-62.

Blagosklonny MV (2004) Flavopiridol, an inhibitor of transcription: implications, problems and solutions. Cell Cycle 3: 1537-1542.

Bose P, Perkins EB, Honeycut C, Wellons MD, Stefan T, Jacobberger JW, Kontopodis E, Beumer JH, Egorin MJ, Imamura CK, Douglas Figg Sr W, Karp JE, Koc ON, Cooper BW, Luger SM, Colevas AD, Roberts JD, Grant S (2012) Phase I trial of the combination of flavopiridol and imatinib mesylate in patients with $\mathrm{Bcr}-\mathrm{Abl}+$ hematological malignancies. Cancer Chemother Pharmacol 69: 1657-1667.

Byrd JC, Lin TS, Dalton JT, Wu D, Phelps MA, Fischer B, Moran M, Blum KA, Rovin B, Brooker-Mceldowney M, Broering S, Schaaf LJ, Johnson AJ, Lucas DM, Heerema NA, Lozanski G, Young DC, Suarez JR, Colevas AD, Grever MR (2007) Flavopiridol administered using a pharmacologically derived schedule is associated with marked clinical efficacy in refractory, genetically high-risk chronic lymphocytic leukemia. Blood 109: 399-404.

Dawson MA, Prinjha RK, Dittmann A, Giotopoulos G, Bantscheff M, Chan WI, Robson SC, Chung CW, Hopf C, Savitski MM, Huthmacher C, 
Gudgin E, Lugo D, Beinke S, Chapman TD, Roberts EJ, Soden PE, Auger KR, Mirguet O, Doehner K, Delwel R, Burnett AK, Jeffrey P, Drewes G, Lee K, Huntly BJ, Kouzarides T (2011) Inhibition of BET recruitment to chromatin as an effective treatment for MLL-fusion leukaemia. Nature 478: 529-533.

Delmore JE, Issa GC, Lemieux ME, Rahl PB, Shi J, Jacobs HM, Kastritis E, Gilpatrick T, Paranal RM, Qi J, Chesi M, Schinzel AC, Mckeown MR, Heffernan TP, Vakoc CR, Bergsagel PL, Ghobrial IM, Richardson PG, Young RA, Hahn WC, Anderson KC, Kung AL, Bradner JE, Mitsiades CS (2011) BET bromodomain inhibition as a therapeutic strategy to target c-Myc. Cell 146: 904-917.

Dow EC, Liu H, Rice AP (2010) T-loop phosphorylated Cdk9 localizes to nuclear speckle domains which may serve as sites of active $\mathrm{P}-\mathrm{TEFb}$ function and exchange between the Brd4 and 7SK/HEXIM1 regulatory complexes. J Cell Physiol 224: 84-93.

Engleson J, Soller M, Panagopoulos I, Dahlen A, Dictor M, Jerkeman M (2006) Midline carcinoma with $t(15 ; 19)$ and BRD4-NUT fusion oncogene in a 30-year-old female with response to docetaxel and radiotherapy. $B M C$ Cancer 6: 69.

Filippakopoulos P, Qi J, Picaud S, Shen Y, Smith WB, Fedorov O, Morse EM, Keates T, Hickman TT, Felletar I, Philpott M, Munro S, Mckeown MR, Wang Y, Christie AL, West N, Cameron MJ, Schwartz B, Heightman TD, La Thangue N, French CA, Wiest O, Kung AL, Knapp S, Bradner JE (2010) Selective inhibition of BET bromodomains. Nature 468: 1067-1073.

Floyd SR, Pacold ME, Huang Q, Clarke SM, Lam FC, Cannell IG, Bryson BD, Rameseder J, Lee MJ, Blake EJ, Fydrych A, Ho R, Greenberger BA, Chen GC, Maffa A, Del Rosario AM, Root DE, Carpenter AE, Hahn WC, Sabatini DM, Chen CC, White FM, Bradner JE, Yaffe MB (2013) The bromodomain protein Brd4 insulates chromatin from DNA damage signalling. Nature 498: 246-250.

French CA (2010) Demystified molecular pathology of NUT midline carcinomas. J Clin Pathol 63: 492-496.

French CA (2012) Pathogenesis of NUT midline carcinoma. Annu Rev Pathol 7: $247-265$.

French CA, Ramirez CL, Kolmakova J, Hickman TT, Cameron MJ, Thyne ME, Kutok JL, Toretsky JA, Tadavarthy AK, Kees UR, Fletcher JA, Aster JC (2008) BRD-NUT oncoproteins: a family of closely related nuclear proteins that block epithelial differentiation and maintain the growth of carcinoma cells. Oncogene 27: 2237-2242.

Fujioka N, French CA, Cameron MJ, Kratzke RA (2010) Long-term survival of a patient with squamous cell carcinoma harboring NUT gene rearrangement. J Thorac Oncol 5: 1704-1705.

Grayson AR, Walsh EM, Cameron MJ, Godec J, Ashworth T, Ambrose JM, Aserlind AB, Wang H, Evan GI, Kluk MJ, Bradner JE, Aster JC, French CA (2013) MYC, a downstream target of BRD-NUT, is necessary and sufficient for the blockade of differentiation in NUT midline carcinoma. Oncogene; e-pub ahead of print 22 April 2013; doi:10.1038/ onc.2013.126.

Haack H, Johnson LA, Fry CJ, Crosby K, Polakiewicz RD, Stelow EB, Hong SM, Schwartz BE, Cameron MJ, Rubin MA, Chang MC, Aster JC, French CA (2009) Diagnosis of NUT midline carcinoma using a NUT-specific monoclonal antibody. Am J Surg Pathol 33: 984-991.

Han JY, Lim KY, Yu SY, Yun T, Kim HT, Lee JS (2011) A phase 2 study of irinotecan, cisplatin, and simvastatin for untreated extensive-disease small cell lung cancer. Cancer 117: 2178-2185.

Hindler K, Cleeland CS, Rivera E, Collard CD (2006) The role of statins in cancer therapy. Oncologist 11: 306-315.

Jang MK, Mochizuki K, Zhou M, Jeong HS, Brady JN, Ozato K (2005) The bromodomain protein Brd4 is a positive regulatory component of $\mathrm{P}-\mathrm{TEFb}$ and stimulates RNA polymerase II-dependent transcription. Mol Cell 19: 523-534.

Karp JE, Garrett-Mayer EL, Estey EH, Rudek MA, Smith BD, Greer JM, Drye DM, Mackey K, Dorcy KS, Gore SD, Levis MJ, Mcdevitt MA, Carraway HE, Pratz KW, Gladstone DE, Showell MM, Othus M, Doyle LA, Wright JJ, Pagel JM (2012) Randomized phase II study of two schedules of flavopiridol given as timed sequential therapy with cytosine arabinoside and mitoxantrone for adults with newly diagnosed, poor-risk acute myelogenous leukemia. Haematologica 97: 1736-1742.

Karp JE, Smith BD, Resar LS, Greer JM, Blackford A, Zhao M, Moton-Nelson D, Alino K, Levis MJ, Gore SD, Joseph B, Carraway H, Mcdevitt MA, Bagain L Mackey K, Briel J, Doyle LA, Wright JJ, Rudek MA (2011) Phase 1 and pharmacokinetic study of bolus-infusion flavopiridol followed by cytosine arabinoside and mitoxantrone for acute leukemias. Blood 117: 3302-3310.
Kees UR, Mulcahy MT, Willoughby ML (1991) Intrathoracic carcinoma in an 11-year-old girl showing a translocation t(15;19). Am J Pediatr Hematol Oncol 13: 459-464.

Kubonishi I, Takehara N, Iwata J, Sonobe H, Ohtsuki Y, Abe T, Miyoshi I (1991) Novel t(15;19)(q15;p13) chromosome abnormality in a thymic carcinoma. Cancer Res 51: 3327-3328.

Lin TS, Ruppert AS, Johnson AJ, Fischer B, Heerema NA, Andritsos LA, Blum KA, Flynn JM, Jones JA, Hu W, Moran ME, Mitchell SM, Smith LL, Wagner AJ, Raymond CA, Schaaf LJ, Phelps MA, Villalona-Calero MA, Grever MR, Byrd JC (2009) Phase II study of flavopiridol in relapsed chronic lymphocytic leukemia demonstrating high response rates in genetically high-risk disease. J Clin Oncol 27: 6012-6018.

Lockwood WW, Zejnullahu K, Bradner JE, Varmus H (2012) Sensitivity of human lung adenocarcinoma cell lines to targeted inhibition of BET epigenetic signaling proteins. Proc Natl Acad Sci USA 109: 19408-19413.

Luke JJ, D'adamo DR, Dickson MA, Keohan ML, Carvajal RD, Maki RG, De Stanchina E, Musi E, Singer S, Schwartz GK (2012) The cyclindependent kinase inhibitor flavopiridol potentiates Doxorubicin efficacy in advanced sarcomas: preclinical investigations and results of a phase I dose-escalation clinical trial. Clin Cancer Res 18: 2638-2647.

Mahoney E, Lucas DM, Gupta SV, Wagner AJ, Herman SE, Smith LL, Yeh YY, Andritsos L, Jones JA, Flynn JM, Blum KA, Zhang X, Lehman A, Kong H, Gurcan M, Grever MR, Johnson AJ, Byrd JC (2012) ER stress and autophagy: new discoveries in the mechanism of action and drug resistance of the cyclin-dependent kinase inhibitor flavopiridol. Blood 120: 1262-1273.

Mertens F, Wiebe T, Adlercreutz C, Mandahl N, French CA (2007) Successful treatment of a child with $\mathrm{t}(15 ; 19)$-positive tumor. Pediatr Blood Cancer 49: $1015-1017$.

Mirguet O, Gosmini R, Toum J, Clement CA, Barnathan M, Brusq JM, Mordaunt JE, Grimes R, Crowe M, Pineau O, Ajakane M, Daugan A, Jeffrey P, Cutler L, Haynes A, Smithers N, Chung CW, Bamborough P, Uings IJ, Lewis T, Witherington J, Parr N, Prinjha R, Nicodeme E (2013) Discovery of epigenetic regulator I-BET762: lead optimization to afford a clinical candidate inhibitor of the BET bromodomains. J Med Chem 56: 7501-7515.

Newcomb EW (2004) Flavopiridol: pleiotropic biological effects enhance its anti-cancer activity. Anticancer Drugs 15: 411-419.

Nishiyama A, Dey A, Miyazaki J, Ozato K (2006) Brd4 is required for recovery from antimicrotubule drug-induced mitotic arrest: preservation of acetylated chromatin. Mol Biol Cell 17: 814-823.

Nishiyama A, Dey A, Tamura T, Ko M, Ozato K (2012) Activation of JNK triggers release of brd4 from mitotic chromosomes and mediates protection from drug-induced mitotic stress. PLoS One 7: e34719.

Ott CJ, Kopp N, Bird L, Paranal RM, Qi J, Bowman T, Rodig SJ, Kung AL, Bradner JE, Weinstock DM (2012) BET bromodomain inhibition targets both c-MYC and IL7R in high-risk acute lymphoblastic leukemia. Blood 120: $2843-2852$.

Parry D, Guzi T, Shanahan F, Davis N, Prabhavalkar D, Wiswell D, Seghezzi W, Paruch K, Dwyer MP, Doll R, Nomeir A, Windsor W, Fischmann T, Wang Y, Oft M, Chen T, Kirschmeier P, Lees EM (2010) Dinaciclib (SCH 727965), a novel and potent cyclin-dependent kinase inhibitor. Mol Cancer Ther 9: 2344-2353.

Prinjha RK, Witherington J, Lee K (2012) Place your BETs: the therapeutic potential of bromodomains. Trends Pharmacol Sci 33: 146-153.

Rathkopf D, Dickson MA, Feldman DR, Carvajal RD, Shah MA, Wu N, Lefkowitz R, Gonen M, Cane LM, Dials HJ, Winkelmann JL, Bosl GJ, Schwartz GK (2009) Phase I study of flavopiridol with oxaliplatin and fluorouracil/leucovorin in advanced solid tumors. Clin Cancer Res 15: 7405-7411.

Reynoird N, Schwartz BE, Delvecchio M, Sadoul K, Meyers D, Mukherjee C, Caron C, Kimura H, Rousseaux S, Cole PA, Panne D, French CA, Khochbin S (2010) Oncogenesis by sequestration of CBP/p300 in transcriptionally inactive hyperacetylated chromatin domains. $E M B O \mathrm{~J}$ 29: 2943-2952.

Schroder S, Cho S, Zeng L, Zhang Q, Kaehlcke K, Mak L, Lau J, Bisgrove D, Schnolzer M, Verdin E, Zhou MM, Ott M (2012) Two-pronged binding with bromodomain-containing protein 4 liberates positive transcription elongation factor $\mathrm{b}$ from inactive ribonucleoprotein complexes. J Biol Chem 287: 1090-1099.

Schwartz BE, Hofer MD, Lemieux ME, Bauer DE, Cameron MJ, West NH, Agoston ES, Reynoird N, Khochbin S, Ince TA, Christie A, Janeway KA, Vargas SO, Perez-Atayde AR, Aster JC, Sallan SE, Kung AL, Bradner JE, French CA (2011) Differentiation of NUT midline carcinoma by epigenomic reprogramming. Cancer Res 71: 2686-2696. 
Senderowicz AM, Headlee D, Stinson SF, Lush RM, Kalil N, Villalba L, Hill K, Steinberg SM, Figg WD, Tompkins A, Arbuck SG, Sausville EA (1998) Phase I trial of continuous infusion flavopiridol, a novel cyclin-dependent kinase inhibitor, in patients with refractory neoplasms. J Clin Oncol 16: 2986-2999.

Shah MA, Kortmansky J, Motwani M, Drobnjak M, Gonen M, Yi S, Weyerbacher A, Cordon-Cardo C, Lefkowitz R, Brenner B, O'reilly E, Saltz L, Tong W, Kelsen DP, Schwartz GK (2005) A phase I clinical trial of the sequential combination of irinotecan followed by flavopiridol. Clin Cancer Res 11: 3836-3845.

Shehata BM, Steelman CK, Abramowsky CR, Olson TA, French CA, Saxe DF, Ricketts RR, Katzenstein HM (2010) NUT midline carcinoma in a newborn with multiorgan disseminated tumor and a 2-year-old with a pancreatic/hepatic primary. Pediatr Dev Pathol 13: 481-485.

Tennant DA, Duran RV, Gottlieb E (2010) Targeting metabolic transformation for cancer therapy. Nat Rev Cancer 10: 267-277.

Thomas JP, Tutsch KD, Cleary JF, Bailey HH, Arzoomanian R, Alberti D, Simon K, Feierabend C, Binger K, Marnocha R, Dresen A, Wilding G (2002) Phase I clinical and pharmacokinetic trial of the cyclin-dependent kinase inhibitor flavopiridol. Cancer Chemother Pharmacol 50: 465-472.

Thompson-Wicking K, Francis RW, Stirnweiss A, Ferrari E, Welch MD, Baker E, Murch AR, Gout AM, Carter KW, Charles AK, Phillips MB, Kees UR, Beesley AH (2013) Novel BRD4-NUT fusion isoforms increase the pathogenic complexity in NUT midline carcinoma. Oncogene 32: 4664-4674.

White L, Sterling-Levis K, Kees UR, Tobias V (2001) Medulloblastoma/ primitive neuroectodermal tumour studied as a Matrigel enhanced subcutaneous xenograft model. J Clin Neurosci 8: 151-156.

Whitlock JA, Krailo M, Reid JM, Ruben SL, Ames MM, Owen W, Reaman G (2005) Phase I clinical and pharmacokinetic study of flavopiridol in children with refractory solid tumors: a Children's Oncology Group Study. J Clin Oncol 23: 9179-9186.

Wu SY, Lee AY, Lai HT, Zhang H, Chiang CM (2013) Phospho switch triggers Brd4 chromatin binding and activator recruitment for gene-specific targeting. Mol Cell 49(5): 843-857.

Zuber J, Shi J, Wang E, Rappaport AR, Herrmann H, Sison EA, Magoon D, Qi J, Blatt K, Wunderlich M, Taylor MJ, Johns C, Chicas A, Mulloy JC, Kogan SC, Brown P, Valent P, Bradner JE, Lowe SW, Vakoc CR (2011) RNAi screen identifies Brd4 as a therapeutic target in acute myeloid leukaemia. Nature 478: 524-528.

This work is published under the standard license to publish agreement. After 12 months the work will become freely available and the license terms will switch to a Creative Commons AttributionNonCommercial-Share Alike 3.0 Unported License.

Supplementary Information accompanies this paper on British Journal of Cancer website (http://www.nature.com/bjc) 